\title{
Enhanced Removal Efficiency of Arsenic and Copper from Aqueous Solution Using Activated Acorus calamus Based Adsorbent
}

\author{
A. Chand, ${ }^{\text {a }}$ P. Chand, ${ }^{\mathrm{b}}$ G. G. Khatri, ${ }^{\mathrm{a}}$ and D. R. Paudel ${ }^{\mathrm{a},{ }^{, "}}$ \\ ${ }^{a}$ Department of Chemistry, Tri-Chandra Multiple Campus, \\ Tribhuvan University, Ghantaghar, Kathmandu, Nepal \\ ${ }^{b}$ Department of Biotechnology and Food Science, Norwegian University \\ of Science and Technology, NTNU, N-7491 Trondheim, Norway \\ doi: https://doi.org/10.15255/CABEQ.2021.1943 \\ Original scientific paper \\ Received: March 20, 2021 \\ Accepted: July 29, 2021
}

\begin{abstract}
Water security, due to heavy metal pollution in water resources, has become a serious problem in modern urbanized society. Plants with a good source of cellulose, hemicellulose, pectin, lignin, etc., are the most promising adsorbents for the removal of heavy metals from water. In this work, for the first time, a low-cost local plant named Acorus calamus (AC; flag root or sweet flag) and citric acid modified AC root powder (CAMAC) were used as potential adsorbents. The samples were characterized by SEM, FT-IR, $\mathrm{XRD}$, and the sorption properties were investigated by different parameters, such as solution $\mathrm{pH}$, batch kinetic study, batch isotherm, effect of adsorbent dose, effect of initial concentration, and effect of contact time. The results of ACRP on removal efficiency of copper (II) and arsenic (III) in an aqueous solution showed an excellent adsorption behavior ( $\sim 80 \%$ adsorption efficiency). This study opens up an easy and economical method for the decontamination of harsh polluting metal ions from water.
\end{abstract}

Keywords:

bioadsorption, heavy metal removal, Acorus calamus, water security, batch isotherm

\section{Introduction}

Heavy metal and metalloid pollution of the watercourses and the environment are due to a significant increase in industrial technologies, anthropogenic activities, such as metallurgy and mining, as well as uncontrolled discharge of municipal, industrial, and agricultural wastes ${ }^{1,2}$. Polluted water means a change in its physical, chemical, and biological properties beyond a certain acceptable concentration limit of pollutants given by the World Health Organization (WHO) and Environment Protection Agency (EPA) ${ }^{3}$. Heavy metal contamination is a serious issue regarding water security ${ }^{2}$. When the concentration limit of heavy metal pollutants is surpassed, severe health threats to living organisms result throughout the food chain, water-plants-animals-humans, due to their toxicity, persistence, and non-biodegradability ${ }^{4,5}$. Thus, the synthesis of a stable, earth abundant, low cost, and highly efficient bioadsorbent for water purification and decontamination is essential.

The World Health Organization (WHO) reported that metals like copper $(\mathrm{Cu})$, chromium, iron, nickel, cadmium, mercury, lead, arsenic (As), zinc,

"Corresponding author: E-mail: drpaude1005@gmail.com, dasu.paudel@trc.tu.edu.np etc., are of serious concern ${ }^{6}$. Among them, arsenic and copper contaminants in water are a major threat affecting a large number of people ${ }^{7}$. Some common sources of arsenic contaminants in water are insecticides, pesticides, wastes from mines, smelter, tannery industries, organic and inorganic compounds of arsenic present in the environment ${ }^{8}$. In 1992, the WHO set the provisional guideline value $(\mathrm{GV})$ for arsenic in drinking water at $10 \mu \mathrm{g} \mathrm{L}^{-1}$ or $0.01 \mathrm{mg} \mathrm{L}^{-1}$ based on concerns regarding its carcinogenicity in humans ${ }^{9}$. Trivalent arsenic species are more toxic than arsenate $[\mathrm{As}(\mathrm{V})]$, and even more toxic than the methylated species, dimethylarsinic acid (DMA) and monomethyl arsenic acid (MMA). As(III) is absorbed faster in biological systems than $\mathrm{As}(\mathrm{V})$, as it is lipid-soluble and absorbed through the skin, while $\mathrm{As}(\mathrm{V})$ is absorbed through the gastrointestinal $\operatorname{tract}^{10}$. Similarly, copper contamination in water bodies occurs due to industrial discharges including mining, metal cleaning, plating baths, pulp and paper board mills, refineries, fertilizer manufacturing industries, etc ${ }^{11}$. In 1993, the WHO recommended a provisional health-based guideline value of $2 \mathrm{mg} \mathrm{L}^{-1}$ of copper in drinking water ${ }^{12}$. In most cases, the $\mathrm{Cu}(\mathrm{I})$ ion is subsequently oxidized to $\mathrm{Cu}(\mathrm{II})$ ion, and the cupric ion, $\mathrm{Cu}(\mathrm{II})$, is the most prevalent species found in the environment, and copper in this form is toxic to many living organisms ${ }^{13}$. Due to 
these toxic effects, it is of utmost importance to remove copper and arsenic from wastewater before its transport and cycling into the watercourse.

The water purification technique for heavy metal removal includes reduction, precipitation, ultra-filtration, coagulation, ion-exchange, reverse osmosis, electrodialysis, flotation, and adsorption ${ }^{14}$. Since the effectiveness of these methods has been unsatisfactory to date, the adsorption process by the use of easily available low-cost plant parts, named 'bio-adsorbents' is attracting the concern of research authorities due to easy transfer of toxic ions, simplicity in design, and low investment ${ }^{15,16}$. Therefore, the surface-modified bio-adsorptive materials with sufficient ion exchange sites are the necessity of these times. Biosorption means the metal binding capacity of various plants and lower animals from wastewater or aqueous systems by the physiochemical method, which involves physical and chemical bonding, chelation, precipitation, and complexation mechanisms ${ }^{17}$. In recent times, biosorption has become a preferred method for metal decontamination, especially when dealing with contaminants of dilute solutions ${ }^{18}$. Pehlivan et al. utilized citric acid modified barley straw (BS) as a low-cost biosorbent for the removal of $\mathrm{Cu}(\mathrm{II})$ ions from aqueous solution $^{19}$. El-Araby et al. investigated the adsorption behaviour of copper (II) ions onto sesame husk (SH) from aqueous solutions ${ }^{13}$. Ulfa et al. utilized modified sawdust cellulose and tested the adsorption capacity for $\mathrm{Cu}$ (II) removal from aqueous solution $^{20}$. Similarly, Irem et al. investigated the biosorption potential of orange waste (OW) using synthetic solutions of arsenic and contaminated drinking water. They conducted different types of batch model experiments ${ }^{21}$. Shakoor et al. explored the sorption of arsenate $(\mathrm{As}(\mathrm{V}))$ and arsenite (As(III)) to natural watermelon rind (WMR), xanthated WMR, and citric acid-modified WMR in aqueous solutions ${ }^{22}$. Pholosi et al. compared the enhancement of As(III) adsorption by magnetite immobilized on pine cone (MNP-PCP) with pine cone $(\mathrm{PCP})^{23}$. Oyedeji et al. used the coconut husk as a low-cost natural adsorbent to study the removal of $\mathrm{Cu}(\mathrm{II}), \mathrm{Fe}(\mathrm{III})$ and $\mathrm{Pb}$ from simulated industrial waste effluent ${ }^{24}$. Hence, the surface of bio-adsorbent can be activated with multiple bonding sites by chemical modification, including treatment of bio-adsorbent with chemical agents such as acids, bases, oxidants, or organic compounds, which ultimately leads to higher adsorption capacity in activated bio-adsorbent than in raw bio-adsorbent.

In the present study, we used a chemically modified Acorus calamus root powder as an adsorbent, and the $\mathrm{Cu}(\mathrm{II})$ and $\mathrm{As}(\mathrm{III})$ ions in an aqueous solution as adsorbate. Acorus calamus is commonly known as sweet flag and is termed 'Bojo' in Nepal. Major constituents of Acorus calamus are alcohols, phenols, alkanes, aldehydes, aromatic compounds, secondary alcohols, aromatic amines, and halogen compounds ${ }^{25,26}$. The Acorus calamus root powder was modified with citric acid solution and heated to convert into reactive citric acid anhydride, which can react with cellulosic hydroxyl groups to make an ester linkage and thus introduce carboxyl functional groups into the cellulosic materials. The introduced free carboxyl groups of citric acid increase the net negative charge on the adsorbent surface by increasing the higher sorption capacity of positively charged metal ions onto its surface. Further heat treatment could also lead to cross-linking between two cellulosic molecules. Hence, modification of low-cost biological materials with citric acid would provide improved metal-binding capacity and better mechanical strength due to cross-linking. The sorption property was investigated by studying the effect of contact time, effect of adsorbent dose, effect of $\mathrm{pH}$, adsorption isotherm, effect of initial concentration, and batch kinetics. The adsorbents were characterized by scanning electron microscope (SEM) analysis for surface structure, Fourier transform infrared spectroscopic analysis (FT-IR) for basic chemical groups, and X-ray diffraction analysis (XRD) for the crystallinity of the sample. This work suggests that the use of the chemically modified, easily available plant parts play a profound role in governing the adsorption behavior, which may cause a new paradigm shift for the design and potential application of bio-adsorbents in environmentally friendly water treatment technology.

\section{Materials and methods}

\section{Materials}

The root of Acorus calamus was collected from Kanchanpur, Nepal. Acetic acid, ammonium molybdate, copper sulfate pentahydrate $\left(\mathrm{CuSO}_{4} \cdot 5 \mathrm{H}_{2} \mathrm{O}\right)$, citric acid, arsenic trioxide, sulphuric acid, sodium hydroxide, hydrochloric acid, hydrazine hydride, potassium permanganate, buffer tablet, and liquor ammonia were purchased from E Merck India Limited. The water used in the experiment was distilled water (DI water). All the chemicals were used as received without any further purification.

\section{Preparation of adsorbent}

The Acorus calamus was washed with tap water followed by distilled water. After washing, the roots were allowed to dry in sunlight for 6 days. The dried roots were then ground using a grinder, and sieved to a particle size of less than $180 \mu \mathrm{m}$. 
The powder obtained was washed several times with distilled water, oven-dried, and named as raw adsorbent.

\section{Modification of Acorus calamus root powder by citric acid}

Firstly, $0.5 \mathrm{M}$ citric acid solution was prepared by dissolving $10.5 \mathrm{~g}$ of citric acid monohydrate into $100 \mathrm{~mL}$ of distilled water, then $10 \mathrm{~g}$ of raw Acorus calamus (RAC) powder was mixed thoroughly, and the mixture was allowed to infuse at $60{ }^{\circ} \mathrm{C}$ for $24 \mathrm{~h}$ in the oven. The reaction mixture was further treated for $4 \mathrm{~h}$ by elevating oven temperature to $120^{\circ} \mathrm{C}$. When a thick paste of the mixture was obtained, it was slurred in distilled water for $30 \mathrm{~min}$ and filtered. The modified sample was then washed several times to remove all the unreacted citric acid, and finally the modified $\mathrm{AC}$ was dried in the oven at $60{ }^{\circ} \mathrm{C}$. When the dry modified sample of AC was obtained, it was again ground and sieved to $180 \mu \mathrm{m}$ particle size (CAMAC).

\section{Preparation of reagents}

\section{Preparation of $\mathrm{CuSO}_{4}$ stock solution}

$1000 \mathrm{ppm}$ of $\mathrm{Cu}(\mathrm{II})$ ion solution was prepared by dissolving $3.93 \mathrm{~g}$ of $\mathrm{CuSO}_{4} \cdot 5 \mathrm{H}_{2} \mathrm{O}$ in $1000 \mathrm{~mL}$ of distilled water. This solution was used as a stock solution for copper ions.

\section{Preparation of arsenic (III) stock solution}

$1000 \mathrm{ppm}$ of As(III) solution was prepared by dissolving $1.32 \mathrm{~g}$ of arsenic trioxide $\left(\mathrm{As}_{2} \mathrm{O}_{3}\right)$ in 10 $\mathrm{mL}$ of $1 \mathrm{M} \mathrm{NaOH}$, which was neutralized by adding $1 \mathrm{M} \mathrm{H}_{2} \mathrm{SO}_{4}$. The solution was then made up to the mark in a $1000-\mathrm{mL}$ volumetric flask by adding distilled water.

\section{Batch adsorption study}

In the batch study, generally, a known concentration of metal solution with adjusted $\mathrm{pH}$ is pipetted out in an Erlenmeyer flask and the predetermined amount of adsorbent is added. The flask is shaken for the prescribed length of time and the concentration of adsorbate is determined. The adsorption of adsorbate varies with different parameters such as $\mathrm{pH}$, contact time, adsorbent dose, the concentration of a metal solution, etc.

To know the adsorption mechanism, one of these parameters was varied by keeping all others constant. The adsorption capacity of the adsorbent at equilibrium was determined using the following equation $^{19,27}$.

$$
q_{\mathrm{e}}=\frac{\left(\gamma_{0}-\gamma_{\mathrm{e}}\right) V}{m}\left(\mathrm{mg} \mathrm{g}^{-1}\right)
$$

where $q_{\mathrm{e}}$ is the amount of metal ion adsorbed per unit mass of adsorbent, $m$ is the weight of adsorbent (g), $\gamma_{0}$ is the initial concentration of adsorbate ( $\left.\mathrm{mg} \mathrm{L}^{-1}\right), \gamma_{\mathrm{e}}$ is the equilibrium concentration of adsorbate $\left(\mathrm{mg} \mathrm{L}^{-1}\right), V$ is the volume of adsorbate (L).

The removal percentage of metal ions was calculated using the following equation ${ }^{13,27}$

$$
\% \text { Removal }=\frac{\gamma_{0}-\gamma_{t}}{\gamma_{0}} \cdot 100
$$

where, $\gamma_{t}$ is the concentration of adsorbate $\left(\mathrm{mg} \mathrm{L}^{-1}\right)$ at given time.

\section{Adsorption isotherm}

Langmuir adsorption isotherm

The linear form of this isotherm is represented by the expression (Langmuir 1916) ${ }^{28}$

$$
\begin{aligned}
& \frac{1}{q_{\mathrm{e}}}=\frac{1}{q_{\mathrm{m}} K_{\mathrm{L}} \gamma_{\mathrm{e}}}+\frac{1}{q_{\mathrm{m}}} \\
& \frac{\gamma_{\mathrm{e}}}{q_{\mathrm{e}}}=\frac{1}{q_{\mathrm{m}} K_{\mathrm{L}}}+\frac{\gamma_{\mathrm{e}}}{q_{\mathrm{m}}}
\end{aligned}
$$

where, $\gamma_{\mathrm{e}}$ is unadsorbed adsorbate concentration in solution at equilibrium $\left(\mathrm{mg} \mathrm{L}^{-1}\right), K_{\mathrm{L}}$ is the Langmuir equilibrium constant $\mathrm{L} \mathrm{g}^{-1}, q_{\mathrm{m}}$ is theoretical monolayer saturation capacity.

The linear plot of $\gamma_{\mathrm{e}} / q_{\mathrm{e}}$ vs $\gamma_{\mathrm{e}}$ can be drawn to evaluate the Langmuir constant $q_{\mathrm{m}}$ and $K_{\mathrm{L}}$ from the slop $\left(\frac{1}{q_{\mathrm{m}}}\right)$ and intercept $\left(\frac{1}{q_{\mathrm{m}} K_{\mathrm{L}}}\right)$ respectively.

The essential characteristics of the Langmuir isotherm can be used to predict affinity between adsorbate and adsorbent by using dimensionless constant called separation factor (SF) also known as equilibrium parameter; which is defined by the following equation ${ }^{28,29}$

$$
\mathrm{SF}=\frac{1}{1+K_{\mathrm{L}} \gamma_{0}}
$$

where, $\gamma_{0}$ is the metal ion concentration in an aqueous solution $\left(\mathrm{mg} \mathrm{L}^{-1}\right), K_{\mathrm{L}}$ is the Langmuir adsorption equilibrium constant associated with the relationship between the adsorbent and adsorbate $\left(\mathrm{L} \mathrm{g}^{-1}\right)$, $\mathrm{SF}$ is the separation factor (dimensionless), which indicates the shape of the adsorption isotherms to be either favorable or unfavorable at different initial concentrations.

\section{Freundlich adsorption isotherm:}

Freundlich equation is represented by

$$
q_{\mathrm{e}}=K_{\mathrm{F}} \gamma_{\mathrm{e}}^{1 / n}
$$

where, $K_{\mathrm{F}}$ is Freundlich constant $\left(\mathrm{L} \mathrm{g} \mathrm{g}^{-1}\right), n$ is Freundlich exponent $\left(\mathrm{g} \mathrm{L}^{-1}\right)$. 
The value of these parameters determines the curvature and steepness of the isotherm, and the value of $n$ indicates the affinity of the adsorbate towards the adsorbent. The linear form of this isotherm is expressed as:

$$
\log q_{\mathrm{e}}=\log K_{\mathrm{F}}+\frac{1}{n} \log \gamma_{\mathrm{e}}
$$

Freundlich constants $K_{\mathrm{F}}$ and $n$ represent adsorption potential and adsorption intensity of solid adsorbent, and can be determined from the plot of $\log q_{\mathrm{e}}$ versus $\log \gamma_{\mathrm{e}}$ with intercept $\log K_{\mathrm{F}}$ and slope $1 / n$, respectively. The value of $K_{\mathrm{F}}$ and $n$ determines the curvature and steepness of the isotherm ${ }^{13}$.

\section{Adsorption kinetics}

To know the rate and mechanism of adsorption, different kinetic models are used in practice.

\section{Pseudo-first-order kinetic model}

The pseudo-first-order equation is generally represented as follows ${ }^{30}$ :

$$
\frac{\mathrm{d} q_{t}}{\mathrm{~d} t}=k_{1}\left(q_{\mathrm{e}}-q_{t}\right)
$$

where $q_{\mathrm{e}}$ and $q_{t}$ in $\mathrm{mg} \mathrm{g}^{-1}$ are the amount of metal ion adsorbed per gram on the surface of adsorbent at equilibrium and at time ' $t$ ', respectively, and $k_{1}$ is the equilibrium rate constant of pseudo-first-order adsorption.

After integration and applying boundary conditions $t=0$ to $t=t$ and $q_{t}=0$ to $q_{t}$, the integrated form becomes

$$
\log \left(q_{\mathrm{e}}-q_{t}\right)=\log q_{\mathrm{e}}-k_{1} t / 2.303
$$

$k_{1}$ can be calculated from the graph of $\log \left(q_{\mathrm{e}}-q_{\mathrm{t}}\right)$ against time $(t)$.

\section{Pseudo-second-order kinetic model}

The pseudo-second-order adsorption kinetic rate equation is expressed as:

$$
\frac{\mathrm{d} q}{\mathrm{~d} t}=k_{2}\left(q_{\mathrm{e}}-q_{t}\right)^{2}
$$

After integrating equation (10) for the following boundary conditions $q_{t}=0$ at $t=0, q_{t}=q_{t}$ at $t=$ $t$, and rearranging it

$$
\frac{t}{q_{t}}=\frac{1}{k_{2} q_{\mathrm{e}}{ }^{2}}+\frac{1}{q_{\mathrm{e}}} t
$$

where, $k_{2}$ is the rate constant of pseudo-second-order kinetic model $\left(\mathrm{g} \mathrm{mg}^{-1} \mathrm{~min}^{-1}\right), k_{2}$ and $q_{\mathrm{e}}$ calculation can be determined from the graph of $\frac{\mathrm{t}}{q_{\mathrm{t}}}$ against $\mathrm{t}^{13}$.

\section{Biosorption}

\section{Modification of sample by citric acid}

The proposed crosslinking reaction of Acorus calamus cellulose and citric acid, and the possible mechanism for modification of adsorbent by citric acid is shown below ${ }^{11}$.

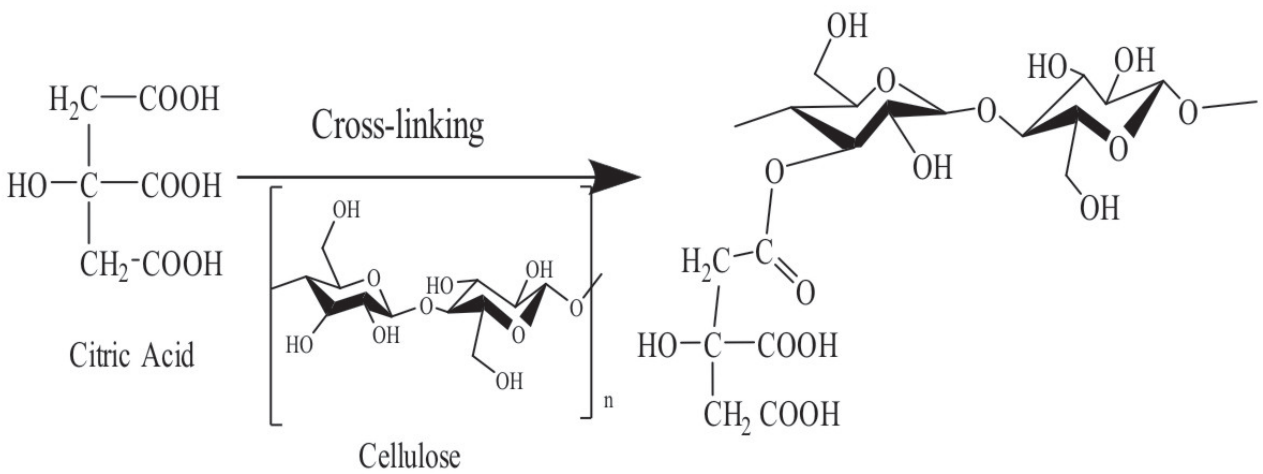

Copper ammonia complexation reaction to determine the maximum wavelength of copper

When concentrated ammonia solution (ammonium hydroxide) is added to copper (II) solution, a powdery, light blue precipitate of copper (II) hydroxide forms.

$$
\left[\mathrm{Cu}\left(\mathrm{H}_{2} \mathrm{O}\right)_{6}\right]^{2+}+2 \mathrm{NH}_{4} \mathrm{OH}(\mathrm{aq}) \rightarrow\left[\mathrm{Cu}\left(\mathrm{H}_{2} \mathrm{O}\right)_{4}(\mathrm{OH})_{2}\right](\mathrm{aq})
$$

Further addition of ammonia causes the formation of a deep blue copper-ammonia complex.

$$
\left[\mathrm{Cu}\left(\mathrm{H}_{2} \mathrm{O}\right)_{4}(\mathrm{OH})_{2}\right](\mathrm{aq})+4 \mathrm{NH}_{4} \mathrm{OH}(\mathrm{aq}) \rightarrow\left[\mathrm{Cu}\left(\mathrm{NH}_{3}\right)_{4}\left(\mathrm{H}_{2} \mathrm{O}\right)_{2}\right]^{2+}(\mathrm{aq})
$$


The intense blue colored copper ammonia complex was used for the determination of the maximum wavelength of the copper ions and the concentration of copper ion in an aqueous solution.

\section{Material characterization}

The XRD characterization was carried out at ambient temperature using a Bruker D8 advance diffractometer in the National Academy of Science and Technology (NAST), Khumaltar, Lalitpur, Nepal. The FT-IR was done at the Central Department of Chemistry, Tribhuvan University, Kirtipur, Kathmandu, Nepal. The FT-IR of dried Acorus calamus sample was obtained with a BRUKER spectrometer model, using the Potassium Bromide ( $\mathrm{KBr}$ ) pellet method. The surface morphologies of the adsorbent samples were characterized by SEM at Sogang University, South Korea. The absorbance and transmittance property of the metal ion was detected using the spectrometer (ELICO/SL NO. 01411). The mechanical shaker, oven, and other instruments available in the department laboratory of the Tri-Chandra Multiple Campus, Kathmandu were used.

\section{Results and discussion}

The raw Acorus calamus root powder (RAC) was chemically modified by treatment with citric acid (Scheme 1, more detail in experimental section), and used as the potential bio-adsorbent (CAMAC) by a simple grinding and etching process. This homemade synthetic strategy suits the largescale application of the biosorbent at a low cost, making it viable for practical application in water/ wastewater treatment and purification.

\section{Sample characterization}

Fourier transform infrared spectroscopic analysis

FT-IR is an important analytical technique used to identify the chemical functional groups on the material. FT-IR spectra of RAC and CAMAC were analyzed in the range of $400-4000 \mathrm{~cm}^{-1}$.

From the FT-IR spectra analysis, the broad absorption band at 3306.68 corresponded to the hydroxyl group $(\mathrm{O}-\mathrm{H})$ of hydrogen-bonded alcohols and phenols and $-\mathrm{N}-\mathrm{H}$ group on the surface of Acorus calamus ${ }^{25}$. The peak at $2930.89 \mathrm{~cm}^{-1}$ was attributed to the $\mathrm{C}-\mathrm{H}$ stretching. The sharp peak at $2344.95 \mathrm{~cm}^{-1}$ was from the $\mathrm{CO}_{2}$ in air $^{13}$. The small absorbances at $1740.80,1614.82,1512.19,1384.74$, and $1240.56 \mathrm{~cm}^{-1}$ corresponded to the aromatic skeletal vibrations, ring breathing with $\mathrm{C}-\mathrm{O}$ stretching in lignins. The bands at 1384 and $1240 \mathrm{~cm}^{-1}$ were assigned to absorption by $\mathrm{C}-\mathrm{H}$ and $\mathrm{C}-\mathrm{O}$ stretching in acetyl group in hemicelluloses, respectively. The strong band at $1028.88 \mathrm{~cm}^{-1}$ was ascribed to $\mathrm{C}-\mathrm{O}$ stretching of alcohol and carboxylic acid in cellulose, hemicelluloses, and lignin or $\mathrm{C}-\mathrm{O}-\mathrm{C}$ stretching in cellulose and hemicellulo$\mathrm{ses}^{20,32}$. A sharp peak at $668.86 \mathrm{~cm}^{-1}$ was due to the presence of halogen compound (alkyl halide) ${ }^{33}$. From the comparison of FT-IR spectra of the raw and citric acid-modified sample, the new peak that appeared at 1720.38 after modification might have been due to $\mathrm{C}-\mathrm{O}$ stretching of carboxyl group $(-\mathrm{C}=\mathrm{O})^{34}$. The reduced peak at $1033.96 \mathrm{~cm}^{-1}$ might have been due to cellulose ring opening by breakage of $\mathrm{C}-\mathrm{O}-\mathrm{C}$ bond. Similar observations for the functional groups on the Acorus calamus extract were analyzed by Mohani et al. ${ }^{25}$, and changes after modification with citric acid by Gong et al., Zhu et al., and Chijioke et al. ${ }^{11,34,35}$ FT-IR spectra of RAC and CAMAC are shown in Fig. 1a-b.

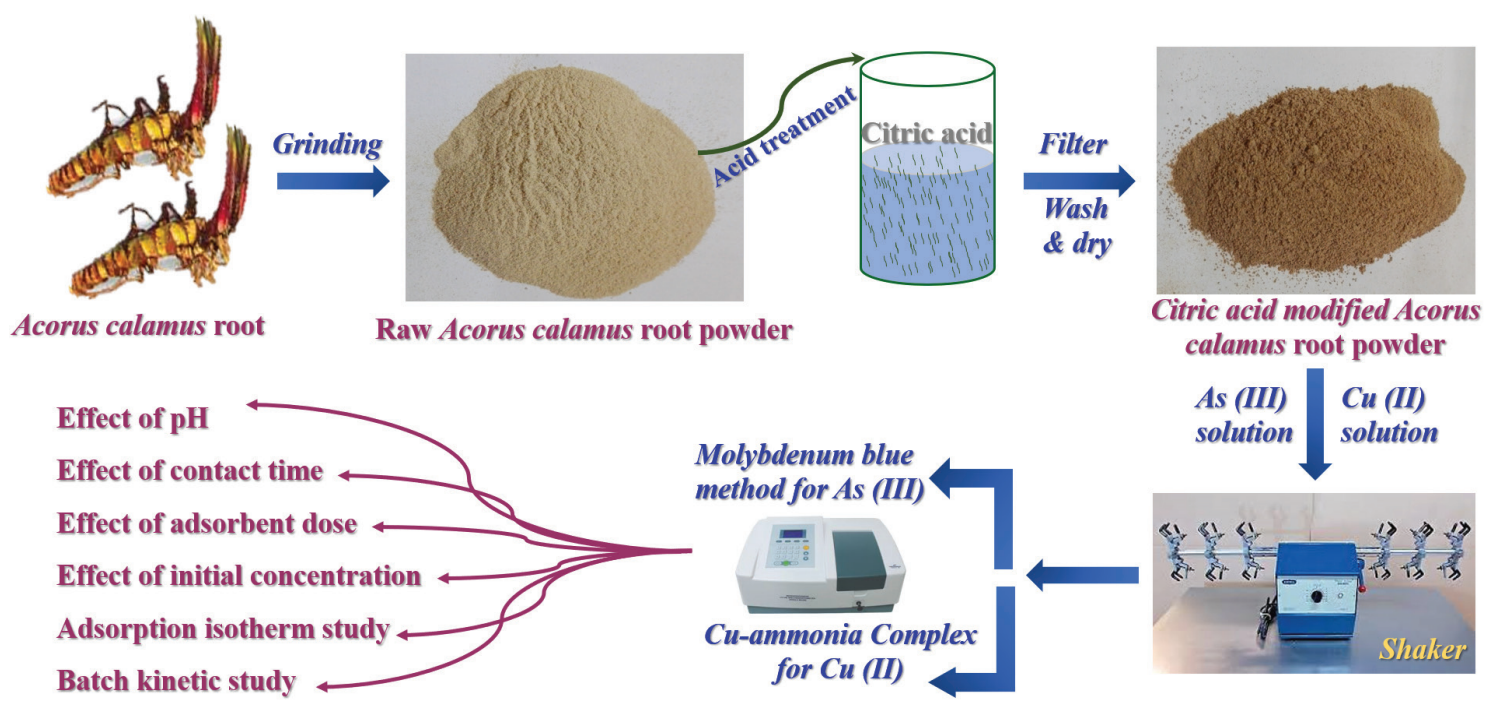

Scheme 1 - Schematic representation of the synthesis and chemical modification of the bio-adsorbent from Acorus calamus root, and application for removal of $\mathrm{Cu}(\mathrm{II})$ and $\mathrm{As}(\mathrm{III})$ ions from aqueous solution 

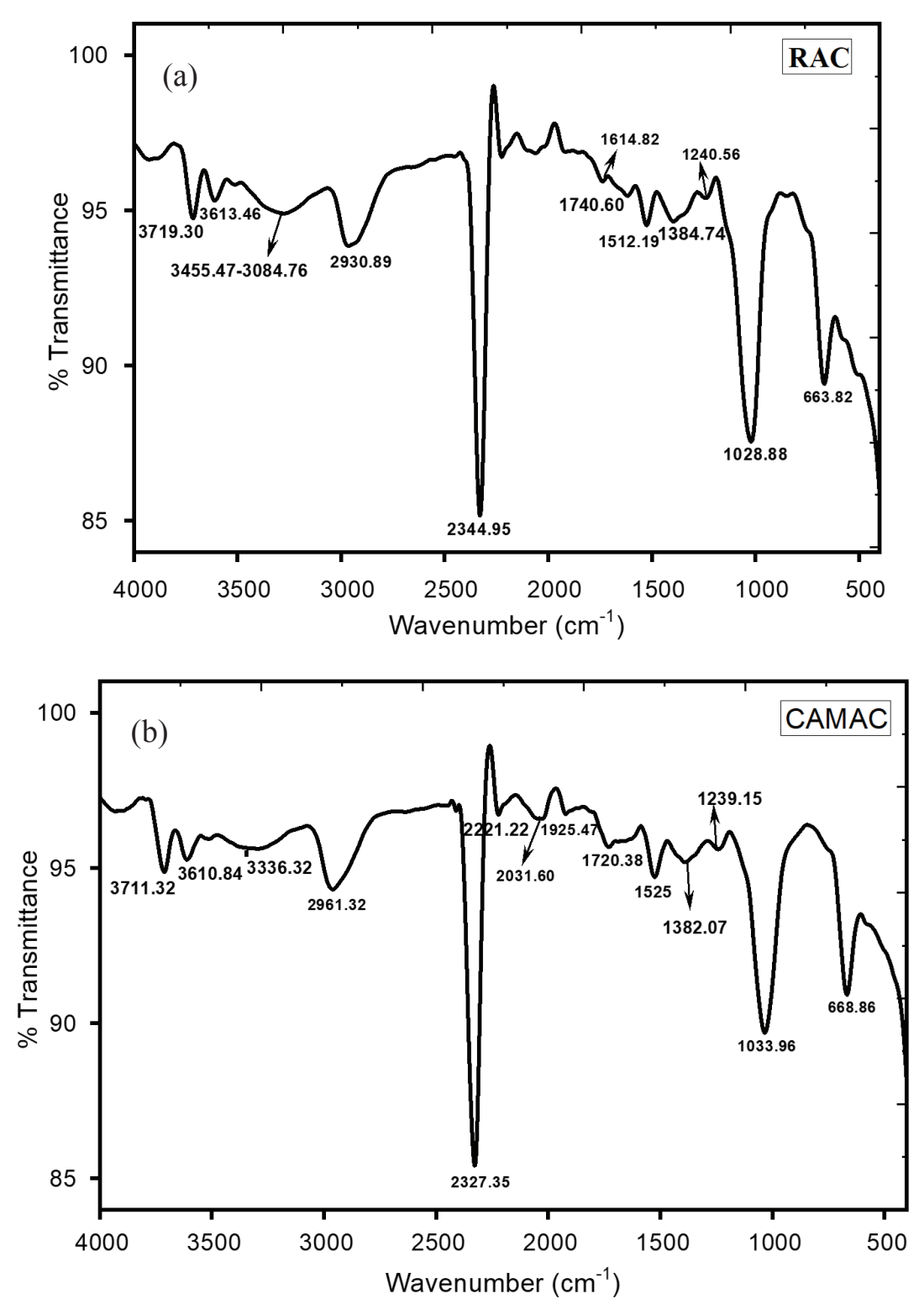

Fig. 1 - FT-IR spectrum of (a) raw Acorus calamus (RAC), (b) citric acid modified Acorus calamus (CAMAC)

From the literature survey, $\mathrm{O}-\mathrm{H},-\mathrm{COOH},-\mathrm{C}-\mathrm{O}$, $-\mathrm{N}-\mathrm{H},=\mathrm{CH}_{2} /-\mathrm{CH}_{3}$ seem to be major functional groups involved in the adsorption of copper and arsenic to the surface of adsorbent among many functional groups present on the Acorus calamus surface $^{13,31}$.

\section{X-ray diffraction analysis}

The crystallographic nature of the biosorbent was inspected by XRD study, and the patterns are represented in Fig. 2. The characteristic low intense diffraction peaks from $9^{\circ}-26^{\circ}$ indicated the slightly crystalline nature of the material. Cellulose present in the biosorbent gives some degree of crystallinity to fiber material as it contains some crystalline-oriented zones. The crystallinity of the adsorbent greatly depends on the composition of lignin, hemicelluloses, and cellulose present in it. The peaks obtained from the samples appeared to be predominantly amorphous. However, some peaks represented characteristics of cellulose crystallinity. The good adsorption capacity of the bio-adsorbents is due to its amorphous nature ${ }^{36,39}$.

\section{Scanning electron microscopy analysis}

SEM was used to analyze the surface morphology and physical properties of the adsorbent, and the images are displayed in Fig. 3a-b. The morphology of both raw and CA-modified Acorus calamus adsorbent exhibited a rough and irregular surface with a distinguished dark spot of pores and cavities, implying the possibility of metal ions being trapped and adsorbed onto the surface. However, CAMAC sample had a more rough and uneven surface with 


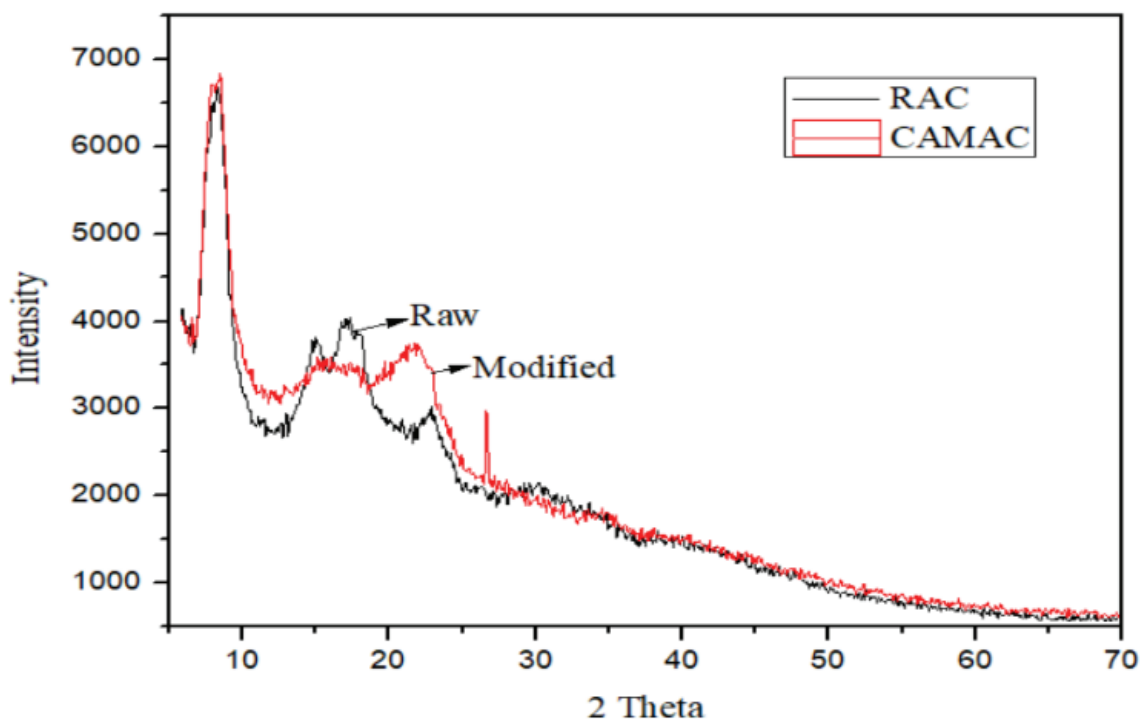

Fig. 2 - X-ray diffraction (XRD) pattern of raw Acorus calamus (RAC), and citric acid modified Acorus calamus (CAMAC)
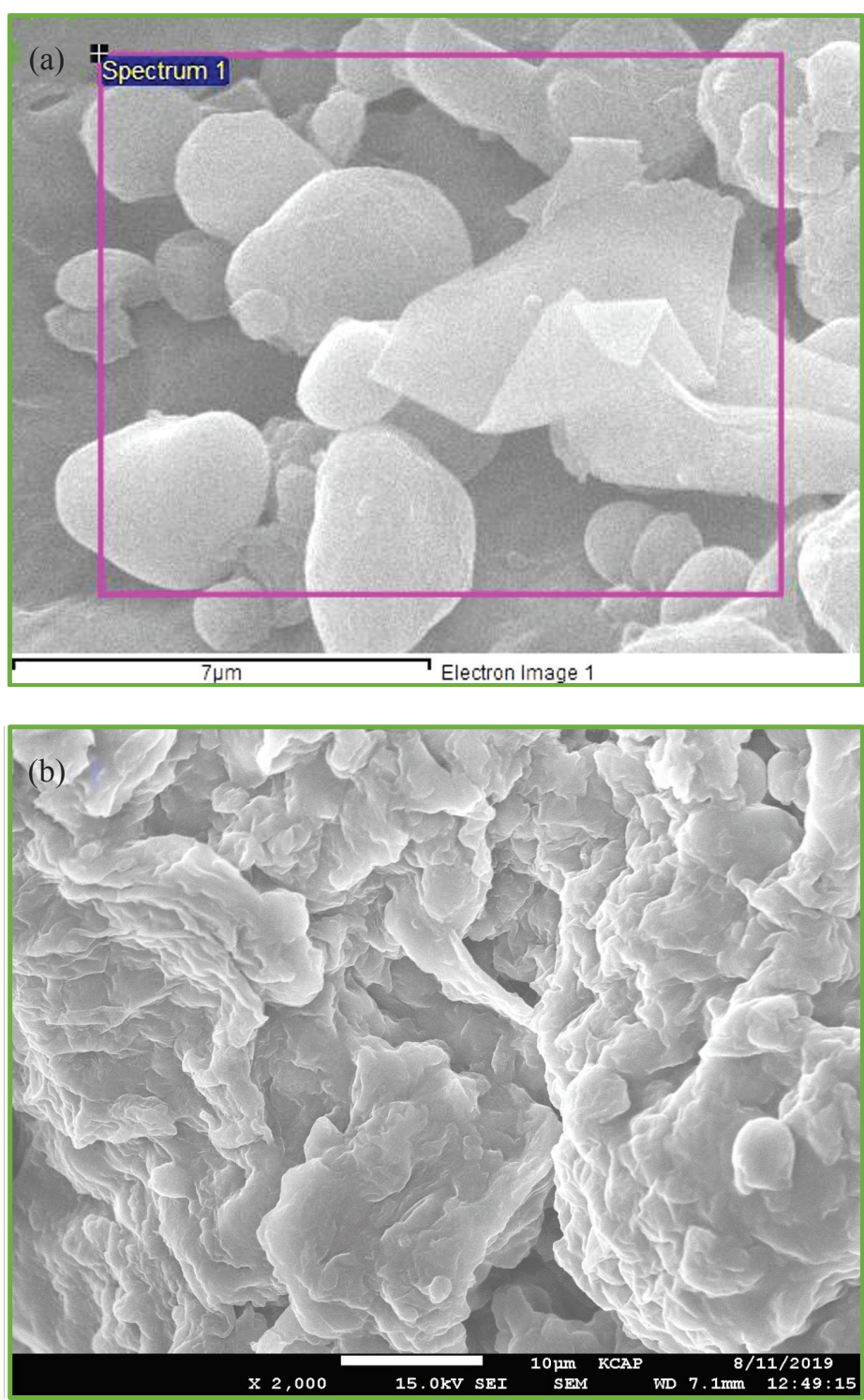

Fig. 3 - Scanning electron microscopic (SEM) image of (a) raw Acorus calamus (RAC), (b) citric acid modified Acorus calamus (CAMAC) 
pores and cavities, indicating the possibility of higher adsorption. This hypothesis was experimentally proved in the present work, where CAMAC had higher removal efficiency than that of RAC.

\section{Determination of $\lambda_{\max }$ and preparation} of calibration curve

The maximum wavelength $\left(\lambda_{\max }\right)$ of As(III) was determined by the molybdenum blue method, in which the arsenomolybdenum blue complex was prepared applying the following procedure.

An acidified solution of As(III) was oxidized to $\mathrm{As}(\mathrm{V})$ using potassium permanganate $\left(\mathrm{KMnO}_{4}\right)$ solution. The As(V) thus formed was then treated with $0.5 \%$ ammonium molybdate, giving a color- less molybdenum heteropolyacid. This acid was then reduced with hydrazine hydrate, giving a blue-colored complex. This complex is called arsenomolybdenum blue complex. The intensity of the color of the complex is directly proportional to the concentration of arsenic. The absorbance was measured spectrophotometrically in the range of 700 to $900 \mathrm{~nm}$, and the absorbance maximum was observed at $820 \mathrm{~nm}$, which is the $\lambda_{\max }$ value for the arsenic-molybdenum blue complex, as shown in Fig. 4a.

For the determination of the maximum wavelength of $\mathrm{Cu}$ (II), the copper-ammonia complex of deep blue color was prepared by reacting copper and 7.5 $\mathrm{M}$ ammonia solution in the ratio of $9: 1$. The
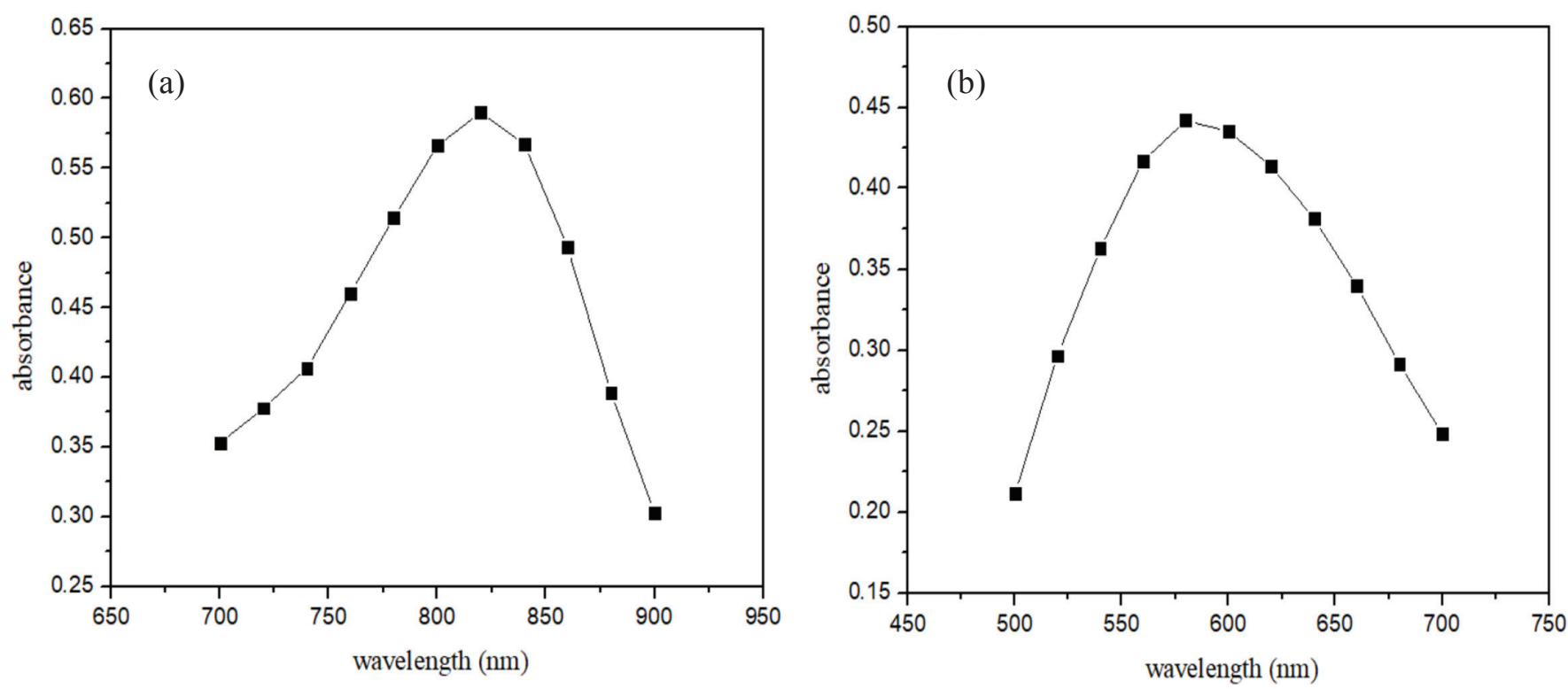

Fig. 4 -Maximum wavelength plots for As(III) (a) and Cu(II) (b)
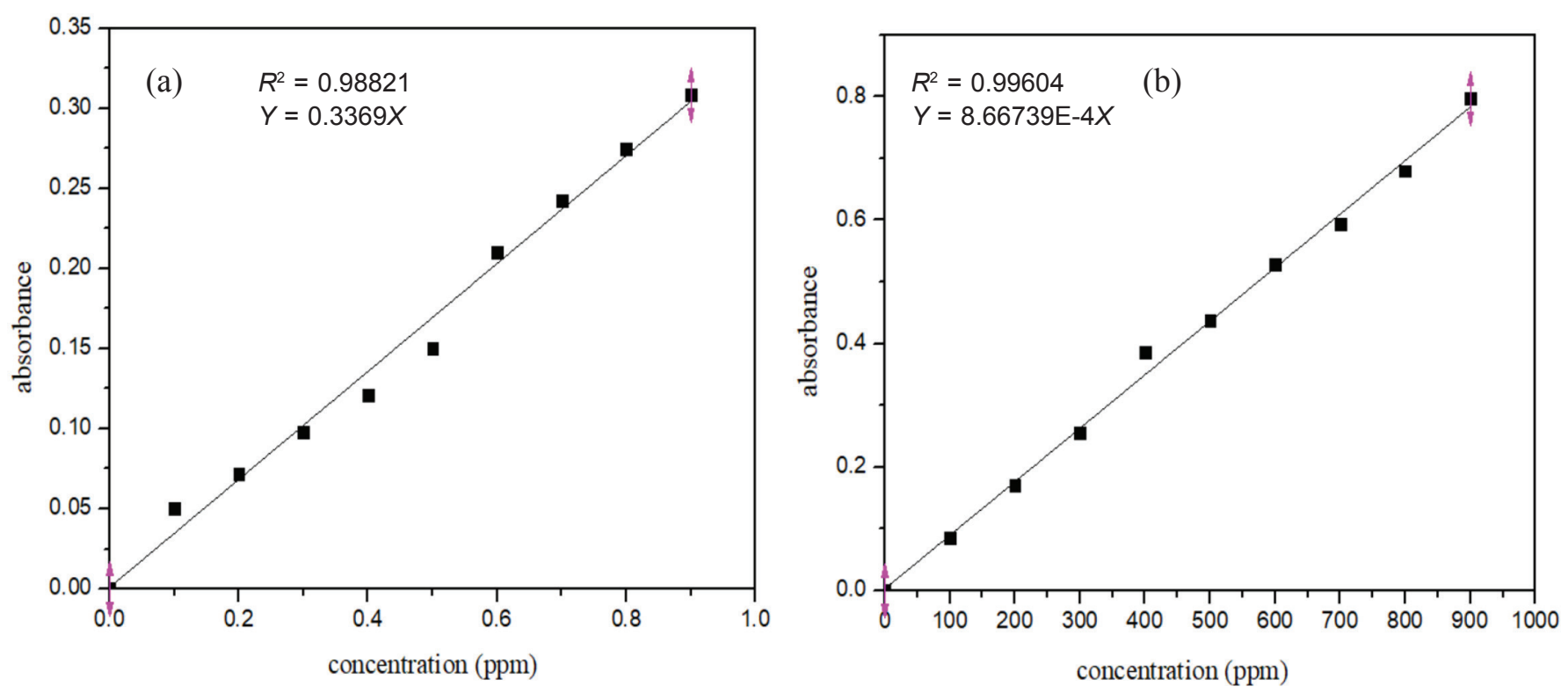

Fig. 5 - Calibration curve of As(III) (a) and Cu(II) (b) 
color intensity of the complex is directly proportional to the concentration of the copper solution. The absorbance was measured spectrophotometrically from 500 to $700 \mathrm{~nm}$. The maximum absorbance was found at $580 \mathrm{~nm}$, which is the $\lambda_{\max }$ value for the copper ammonia complex as shown in Fig. $4 b$.

To construct the calibration curve for the determination of $\mathrm{As}(\mathrm{III})$ and $\mathrm{Cu}(\mathrm{II})$, the absorbance at $\lambda_{\text {max }}$ was measured while varying the concentration of $\mathrm{As}$ (III) and $\mathrm{Cu}$ (II) solution. The calibration curve was constructed by plotting the graph of concentration against absorbance. The calibration curve obtained was linear and obeyed Beer's Lambert's law, as shown in Figs. 5a and b for $\mathrm{As}(\mathrm{III})$ and $\mathrm{Cu}(\mathrm{II})$, respectively.

\section{Effect of $\mathrm{pH}$ on adsorption of $\mathrm{As}$ (III) and $\mathrm{Cu}(\mathrm{II})$}

The $\mathrm{pH}$ of a solution is one of the critical factors in controlling the biosorption of As(III) and $\mathrm{Cu}(\mathrm{II})$. It is believed to influence the surface charge of the functional group of the adsorbent, the degree of ionization, and the speciation of the adsorbate. The effect of $\mathrm{pH}$ on the adsorption of As(III) and $\mathrm{Cu}(\mathrm{II})$ on crude Acorus calamus (RAC) root and Acorus calamus (CAMAC) root modified with citric acid is shown in Figs. 6a and $b$ for the adsorption of $\mathrm{As}(\mathrm{III})$ and $\mathrm{Cu}(\mathrm{II})$, respectively. This shows the relationship between percent removal $(\%, R)$ and $\mathrm{pH}$. The effect of $\mathrm{pH}$ on removal efficiency of $\mathrm{As}(\mathrm{III})$ and $\mathrm{Cu}(\mathrm{II})$ was carried out by contacting $0.25 \mathrm{mg}$ of adsorbent with $20 \mathrm{~mL}$ of $10 \mathrm{mg} \mathrm{L}^{-1}$ and $100 \mathrm{mg} \mathrm{L}^{-1}$ for $6 \mathrm{~h}$, varying $\mathrm{pH}$ from 2 to 9 and 2 to 6 for $\mathrm{As}(\mathrm{III})$ and $\mathrm{Cu}(\mathrm{II})$ respectively. The maximum adsorption percentage for $\mathrm{As}(\mathrm{III})$ was $72.96 \%$ and $81.95 \%$ at $\mathrm{pH} 7$, and for $\mathrm{Cu}(\mathrm{II}) 77.154 \%$ and
$88.23 \%$ at $\mathrm{pH} 6$ on RAC and CAMAC, respectively. Therefore, $\mathrm{pH} 7$ for $\mathrm{As}(\mathrm{III})$ and $\mathrm{pH} 6$ for $\mathrm{Cu}(\mathrm{II})$ were reported as the optimum $\mathrm{pH}$ for maximum adsorption. Above $\mathrm{pH} 6$, the $\mathrm{Cu}(\mathrm{II})$ precipitates forming an insoluble $\mathrm{Cu}(\mathrm{OH})_{2}{ }^{11}$. The adsorption of $\mathrm{Cu}$ (II) ions increases with increasing $\mathrm{pH}$, as shown in Fig. 6b. The lower adsorption at acidic $\mathrm{pH}$ was due to the higher concentration of $\mathrm{H}^{+}$ions competing with the metal ions ${ }^{13,37}$. The maximum adsorption of $\mathrm{As}$ (III) was obtained at $\mathrm{pH} 7$ (which is a neutral $\mathrm{pH}$ ) by RAC and CAMAC. This may have been due to the presence of monoionic $\left(\mathrm{H}_{2} \mathrm{AsO}_{3}{ }^{-}\right)$ and neutral $\left(\mathrm{H}_{3} \mathrm{AsO}_{3}\right) \mathrm{As}(\mathrm{III})$ species. These species are responsible for the adsorption of As(III) on the adsorbent by replacing the hydroxyl group or water molecules, and neutral As(III) molecules interact with unprotonated amino groups of the adsorbent ${ }^{22,38}$.

\section{Effect of adsorbent dose on adsorption of As(III) and $\mathrm{Cu}(\mathrm{II})$}

The effect of adsorbent dosage on the percentage removal of $\mathrm{As}(\mathrm{III})$ and $\mathrm{Cu}$ (II) ions was studied by varying the adsorbent dosage from 25 to $150 \mathrm{mg}$ using a fixed volume of $20 \mathrm{~mL}$ of $100 \mathrm{mg} \mathrm{L}^{-1} \mathrm{Cu}$ (II) and $10 \mathrm{mg} \mathrm{L}^{-1} \mathrm{As}(\mathrm{III})$ at optimum $\mathrm{pH}$. The relationship between adsorbent dose and percent removal is shown in Figs. 7a and b for RAC and CAMAC, respectively.

With increasing adsorbent dose, the percentage removal of adsorbed $\mathrm{As}$ (III) and $\mathrm{Cu}(\mathrm{II})$ had also increased. This indicated an increase in adsorbent surface area and the availability of more binding sites. However, a further increase in adsorbent dose had no significant effect on the removal of As(III) and
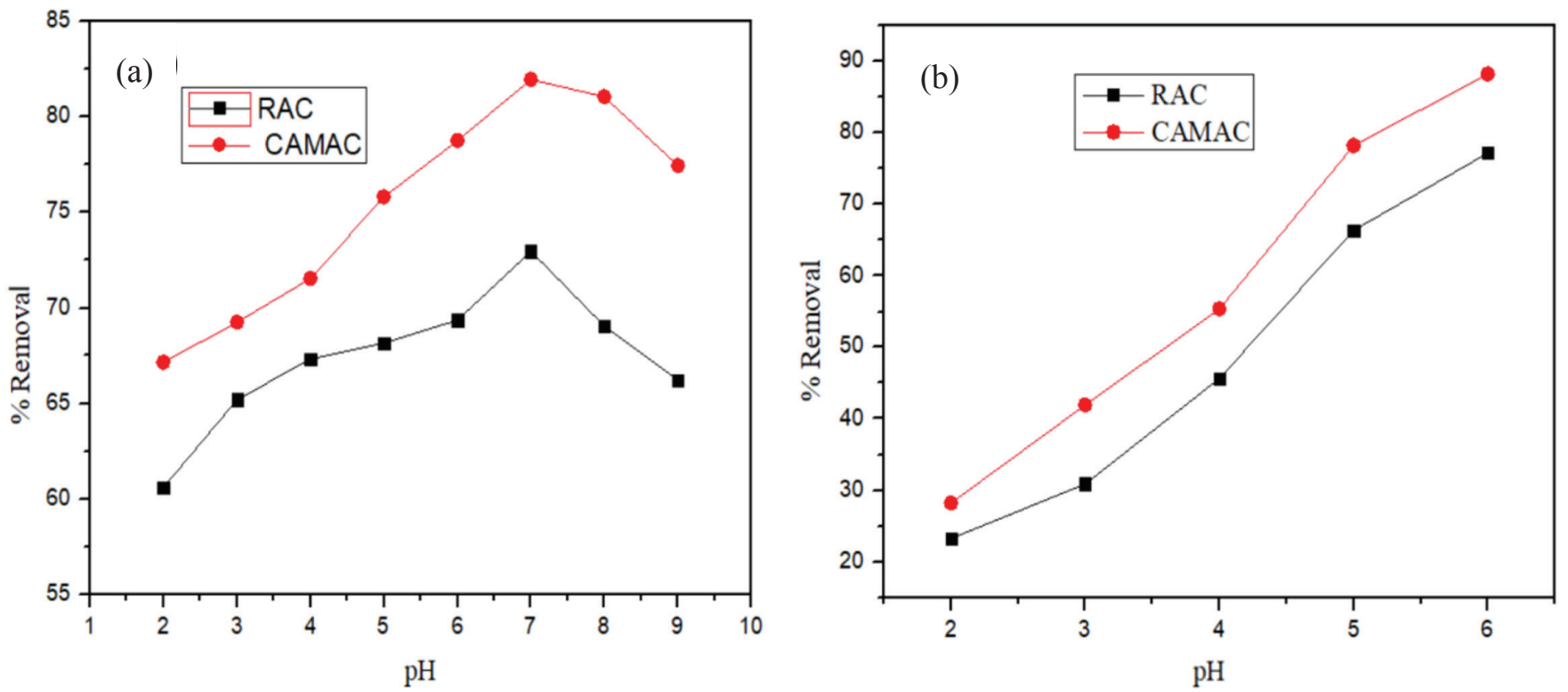

Fig. 6 - Effect of pH on adsorption of As(III) (a) and Cu(II) (b) onto RAC and CAMAC 
$\mathrm{Cu}(\mathrm{II})$. Therefore, in the present study, $125 \mathrm{mg}$ and $100 \mathrm{mg}$ of biosorbent were found to be the optimum dose for $\mathrm{Cu}(\mathrm{II})$ and $\mathrm{As}(\mathrm{III})$, respectively. Beyond this dose, there was less removal of As(III) and $\mathrm{Cu}(\mathrm{II})$ ions due to the crowding of adsorbent particles on the surface of the biosorbent.

\section{Effect of contact time on adsorption of As(III) and $\mathrm{Cu}(I I)$}

The percentage removal of metal ions at different times can be determined by varying the contact time of the adsorbent with an aqueous metal solution. It is one of the most important parameters for studying the adsorption process. The effect of time was studied by experimenting with a $20-\mathrm{mL}$ metal solution containing $25 \mathrm{mg}$ adsorbent at the initial concentration of $10 \mathrm{mg} \mathrm{L}^{-1}$ and $100 \mathrm{mg} \mathrm{L}^{-1}$, at optimum $\mathrm{pH} 7$ and $\mathrm{pH} 6$ for $\mathrm{As}(\mathrm{III})$ and $\mathrm{Cu}(\mathrm{II})$, respectively. The percentage removal of arsenic and copper by crude and modified Acorus calamus is shown in Figs. $8 \mathrm{a}$ and $\mathrm{b}$.

From the figure, the equilibrium time for $\mathrm{Cu}(\mathrm{II})$ is $6 \mathrm{~h}$ on both RAC and CAMAC, while for As(III) it is $5 \mathrm{~h}$ on RAC and $4 \mathrm{~h}$ on CAMAC. The adsorption rate was very fast initially, and then gradually decreased because there were limited binding sites, and the remaining unoccupied surface sites were difficult to be occupied by metal ions due to the repulsive forces between the adsorbed metal ion on the solid surface and the remaining metal ion in the liquid phase ${ }^{40}$.
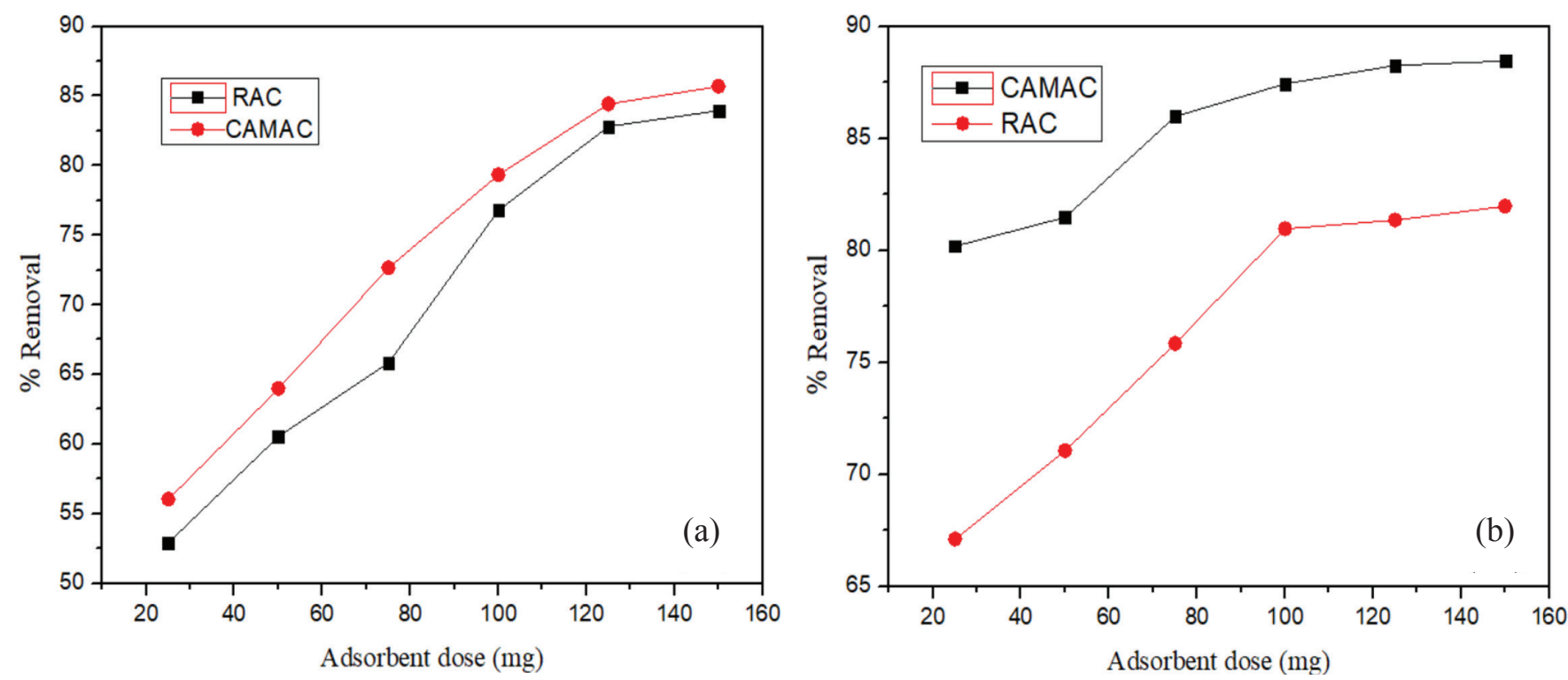

Fig. 7 - Effect of adsorbent dose for adsorption of Cu(II) (a) and As(III) (b) onto RAC and CAMAC
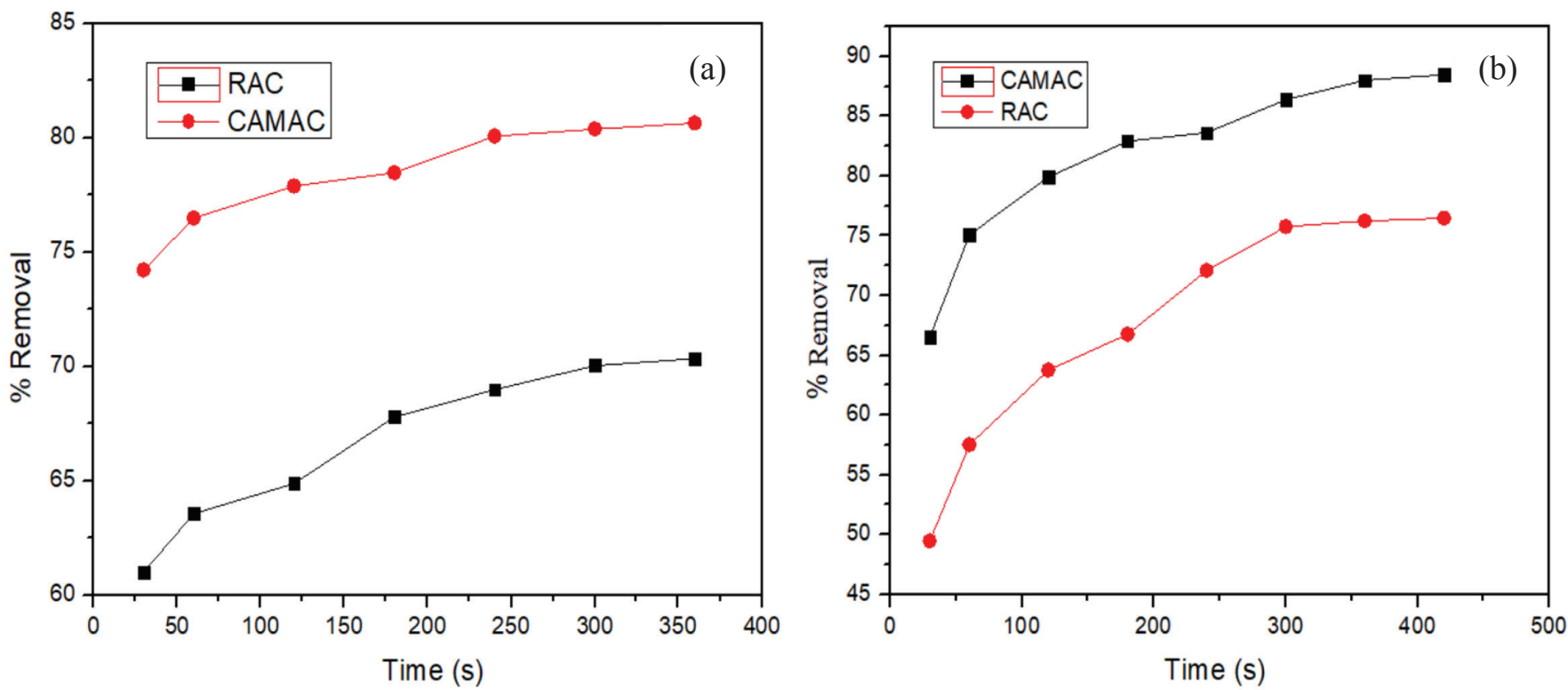

Fig. 8 - Effect of time on adsorption of As(III) (a) and for Cu(II) (b) onto RAC and CAMAC 


\section{Effect of initial concentrations}

The effect of the concentration of $\mathrm{Cu}(\mathrm{II})$ and As(III) is shown in Figs. 9a and b, respectively. The experiment was carried out varying the initial concentration of copper ion $(40,60,80,100,120,140$ $\mathrm{ppm})$ and arsenic ion $(2,4,6,8,10,12,14 \mathrm{ppm})$ at constant time, adsorbent dose, and at their optimum $\mathrm{pH}$. The graph reveals that the adsorbed amount of metal ions per unit mass of adsorbent $\left(q_{\mathrm{e}}\right)$ increased with an increase in the initial concentration of $\mathrm{Cu}$ (II) and As(III) solutions.

From the results, it was observed that, when the initial concentration of $\mathrm{Cu}$ (II) was changed from $40 \mathrm{mg} \mathrm{L}^{-1}$ to $140 \mathrm{mg} \mathrm{L}^{-1}$, the adsorbed amount increased from $6.823 \mathrm{mg} \mathrm{g}^{-1}$ to $15.331 \mathrm{mg} \mathrm{g}^{-1}$ for $\mathrm{RAC}$, and $7.631 \mathrm{mg} \mathrm{g}^{-1}$ to $16.969 \mathrm{mg} \mathrm{g}^{-1}$ for CAMAC. Similarly, when the initial concentration of As(III) was changed from $2 \mathrm{mg} \mathrm{L}^{-1}$ to $14 \mathrm{mg} \mathrm{L}^{-1}$, the adsorbed amount increased from $0.656 \mathrm{mg} \mathrm{g}^{-1}$ to $3.379 \mathrm{~g} \mathrm{~g}^{-1}$ on RAC, and from $0.696 \mathrm{mg} \mathrm{g}^{-1}$ to $3.946 \mathrm{mg} \mathrm{g}^{-1}$ on CAMAC, at corresponding optimum $\mathrm{pH}$. Increasing the concentration of metal ions increases the driving force of mass transfer. As a result, the rate at which $\mathrm{As}$ (III)oxyanions and $\mathrm{Cu}$ (II) ions moved from the bulk of the solution to the particle surface had increased, and adsorption increased.

\section{Adsorption isotherm study}

An adsorption isotherm is a primary tool for understanding the surface characteristics of the adsorbent, and describes the distribution of metal ions between the liquid and solid phases at equilibrium, the nature of the interaction between the metal ion, and adsorbent. To determine the adsorption system, the data were fitted by applying different models such as Langmuir and Freundlich isotherm. The adsorption of $\mathrm{Cu}(\mathrm{II})$ and $\mathrm{As}(\mathrm{III})$ on RAC and CAMAC gave a linear relationship with the Langmuir and Freundlich isotherms. The resulting data are shown in fitted plots in Figs. 10a, b, c, and d.

The $R_{\mathrm{L}}$ values from the Langmuir isotherm model were determined to be 0.174 and 0.143 for As(III) on RAC and CAMAC, respectively. Simultaneously, the $R_{\mathrm{L}}$ values for $\mathrm{Cu}(\mathrm{II})$ were determined to be 0.195 and 0.050 using RAC and CAMAC, respectively. These values are in the range $0<R_{\mathrm{L}}<1$, indicating a favorable process and the adsorption data fit well into the Langmuir adsorption isotherm. From the plot of the Langmuir and Freundlich isotherm data for $\mathrm{Cu}$ (II) and $\mathrm{As}(\mathrm{III})$, it was found that the correlation coefficient $\left(R^{2}\right)$ of the Langmuir isotherm had a high value for both metal ions. This indicates that the Langmuir isotherm model is more suitable for the adsorption of $\mathrm{Cu}(\mathrm{II})$ and $\mathrm{As}(\mathrm{III})$.

\section{Batch kinetic studies}

Pseudo-first- and pseudo-second-order kinetic models used to understand the properties and mechanism of adsorption of $\mathrm{As}(\mathrm{III})$ and $\mathrm{Cu}$ (II) on RAC and CAMAC are shown in Figs. 11a, b, c, and d.

From the kinetic plots for the adsorption of $\mathrm{As}(\mathrm{III})$ and $\mathrm{Cu}(\mathrm{II})$, it was found that the value of the correlation coefficients $\left(R^{2}\right)$ for the pseudo-second-order was higher (close to 1) than that of the pseudo-first-order. Therefore, the adsorption of $\mathrm{As}(\mathrm{III})$ and $\mathrm{Cu}$ (II) on RAC and CAMAC follows the pseudo-second-order kinetic model.
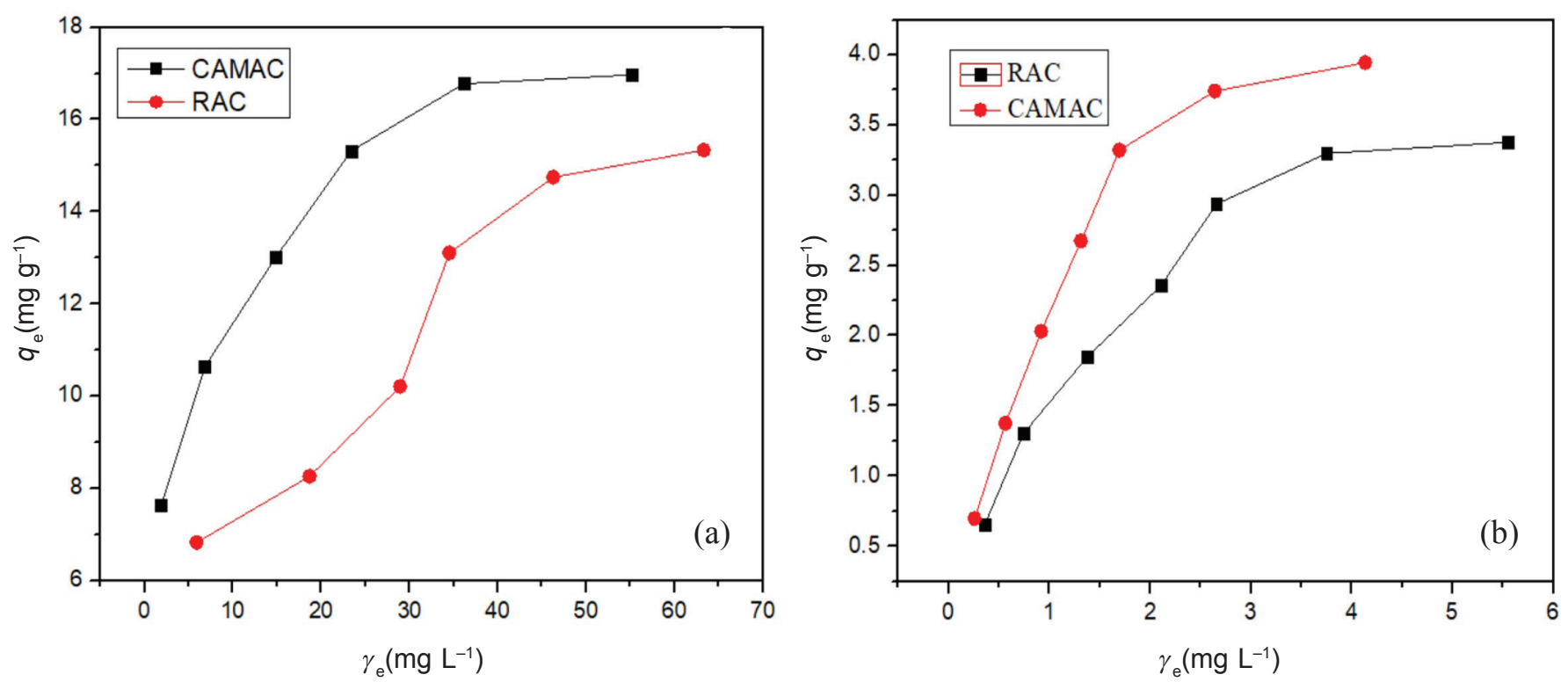

Fig. 9 - Effect of initial concentration on adsorption of Cu(II) ions (a) and for As(III) ions (b) onto RAC and CAMAC 

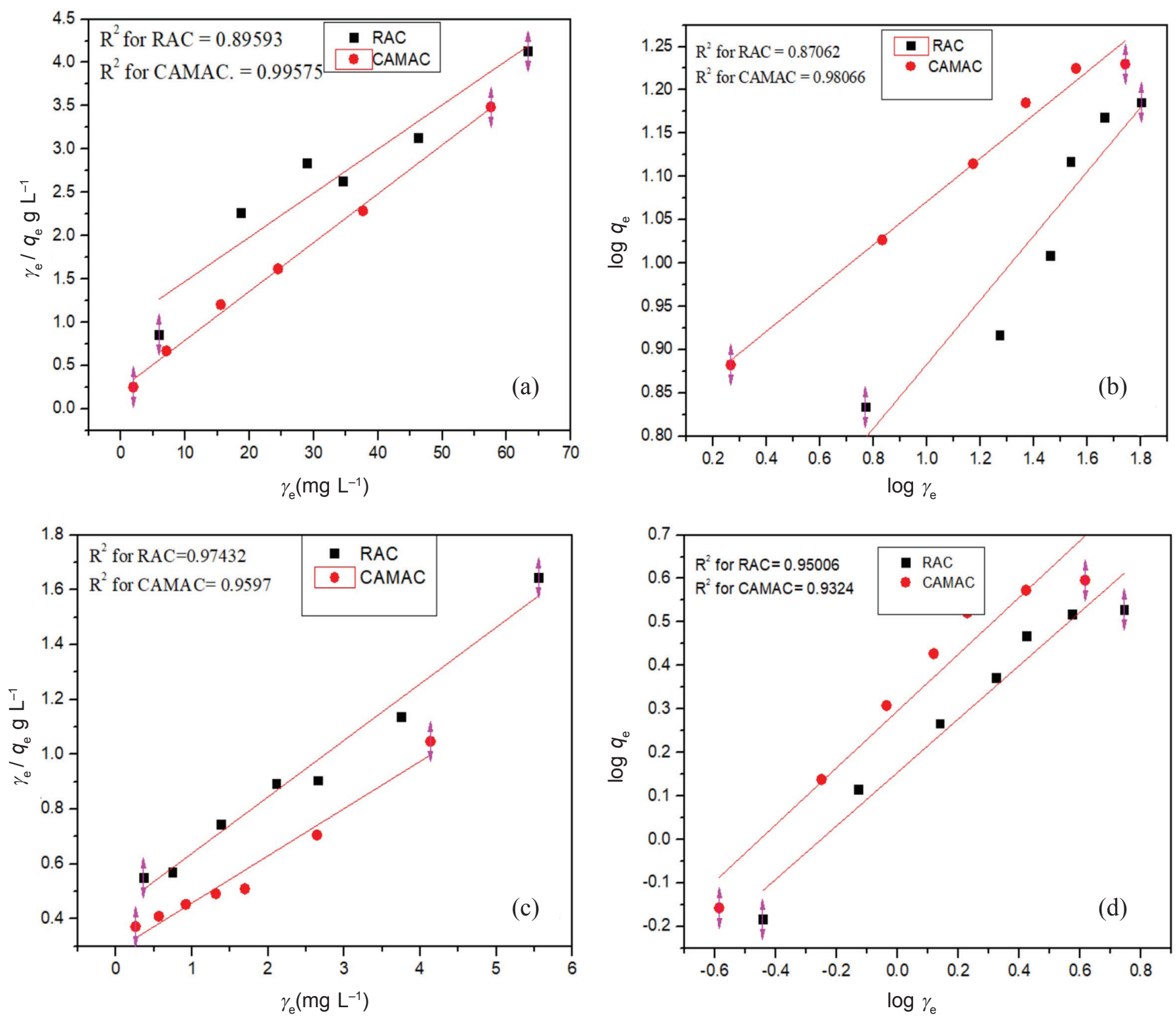

Fig. 10 - Langmuir adsorption isotherm of $C u(I I)$ (a), As(III) (c), and Freundlich adsorption isotherm of Cu(II) (b), As(III) (d) onto RAC and CAMAC

\section{Conclusion}

In the present study, Acorus calamus root powder was modified with citric acid, and both the raw (RAC) and modified (CAMAC) samples were characterized using Fourier transform infrared spectroscopy (FT-IR), X-ray diffraction analysis (XRD), and scanning electron microscopy (SEM). The functional groups present on the adsorbent were characterized by FTIR analysis revealing that there was a large number of carboxyl and hydroxyl groups on the surface of the adsorbent, which was possibly responsible for the metal ion adsorption through chemisorption in an aqueous solution. The surface structure was characterized by XRD analysis. The adsorbents were found to be largely amorphous; however, some peaks were characteristic of cellulose crystallinity. In addition, the surface morphology analyzed by SEM exhibited a rough and irregular surface with a distinguished dark spot of pores and cavities. These conditions are good for metal adsorption.

The removal of $\mathrm{Cu}$ (II) and $\mathrm{As}(\mathrm{III})$ by Acorus calamus root and its chemically modified form was investigated. Their efficiency was compared by varying different parameters. The $\mathrm{pH}$ was found to be the most important factor affecting the adsorption of metal ions. The optimum adsorption capacity was obtained at pH 6 with $77.154 \%$ and $88.23 \%$ adsorption for $\mathrm{Cu}(\mathrm{II})$ and $\mathrm{pH} 7$ with $72.96 \%$ and $81.95 \%$ adsorption for As(III) for both RAC and CAMAC, respectively. The adsorption capacity of the adsorbent increased by almost $10 \%$ after modification. The optimum dose for $\mathrm{Cu}(\mathrm{II})$ and $\mathrm{As}(\mathrm{III})$ 

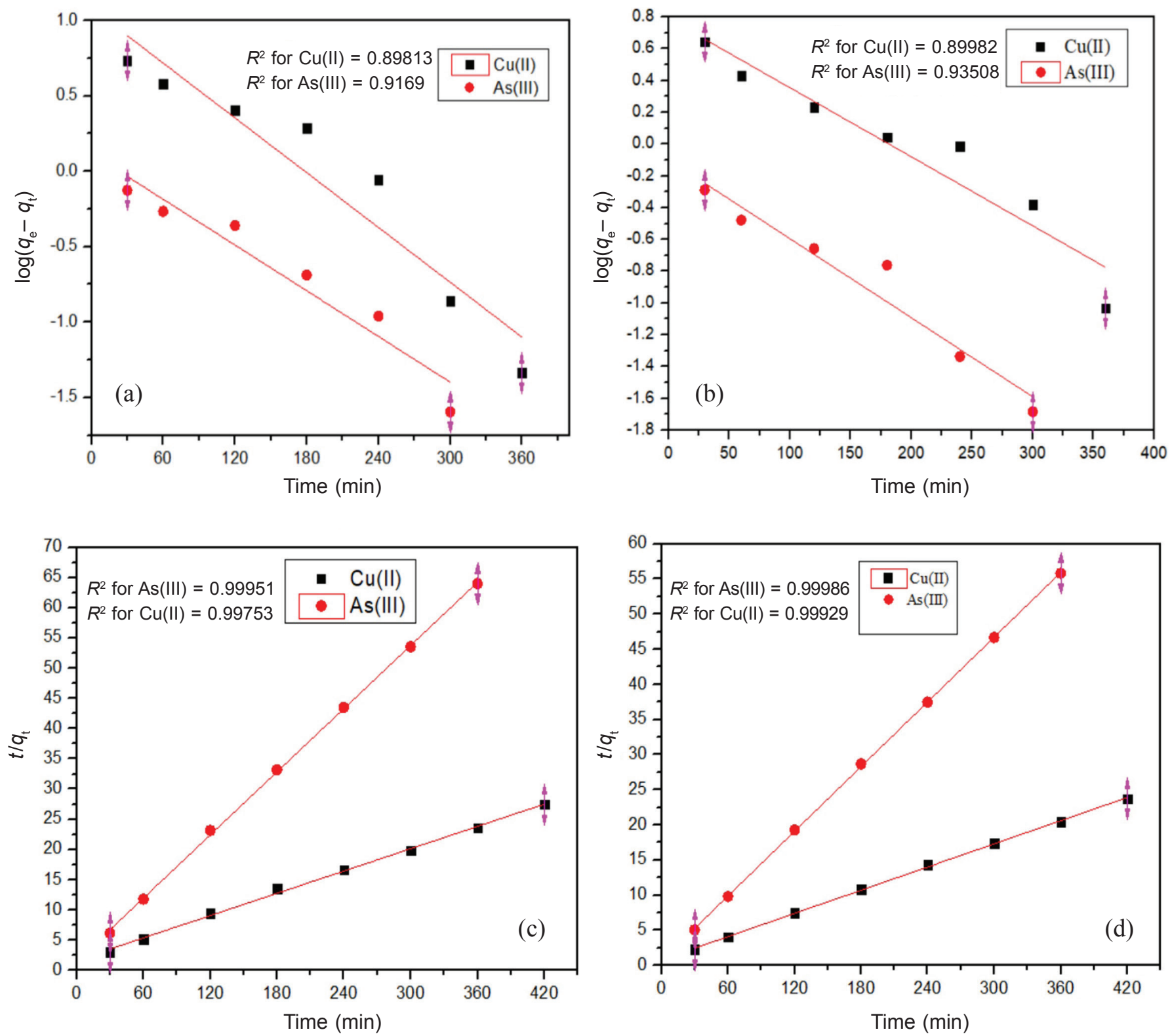

Fig. 11 - Pseudo first-order kinetic model for adsorption of Cu(II) and As(III) on RAC (a), CAMAC (b), and pseudo-second-order kinetic model for adsorption of Cu(II) and As(III) on RAC (c), and CAMAC (d)

was found to be $125 \mathrm{mg}$ and $100 \mathrm{mg}$ for RAC and CAMAC, respectively. The equilibrium time for $\mathrm{Cu}(\mathrm{II})$ on RAC and CAMAC was $6 \mathrm{~h}$, while it was $5 \mathrm{~h}$ for As(III) on RAC and $4 \mathrm{~h}$ on CAMAC. The maximum adsorption capacity of RAC and CAMAC was found to be $15.331 \mathrm{mg} \mathrm{g}^{-1}$ and 16.969 $\mathrm{mg} \mathrm{g}^{-1}$ for $\mathrm{Cu}(\mathrm{II})$, and $3.39 \mathrm{mg} \mathrm{g}^{-1}$ and $3.74 \mathrm{mg} \mathrm{g}^{-1}$ for As(III), respectively. The experimental data were better fitted with the Langmuir adsorption isotherm model for the adsorption of $\mathrm{Cu}$ (II) and As(III). From the kinetics study, the adsorption of both $\mathrm{Cu}(\mathrm{II})$ and $\mathrm{As}(\mathrm{III})$ followed pseudo-second-order kinetics. From this work, it may be concluded that crude and chemically modified Acorus calamus root is a suitable adsorbent for the adsorption of
$\mathrm{Cu}(\mathrm{II})$ and $\mathrm{As}(\mathrm{III})$ from water with high efficiency and fast uptake capacity. Moreover, it is clear that citric acid modification increases the adsorption efficiency of metal ions by increasing the metal exchange site on the surface of the adsorbent.

\section{ACKNOWLEDGEMENTS}

We would like to acknowledge the Department of Chemistry, Tri-Chandra Multiple Campus (for instrumentation), Central Department of Chemistry, Kritipur; National Academy of Science and Technology, Khumaltar; Department of Artificial Photosynthesis, Sogang University, Seoul, South Korea (for characterization of samples). 


\section{DECLARATION OF INTERESTS}

The authors declare that they have no known competing financial interests or personal relationships that could have appeared to influence the work reported in this paper.

\section{References}

1. Al-Qodah, Z., Yahya, M. A., Al-Shannag, M., On the performance of bioabsorption processes for heavy metal ions removal by low-cost agricultural and natural by-products bio adsorbent: A review, Desalin. Water Treat. 85 (2017) 339. doi: https://doi.org/10.5004/dwt.2017.21256

2. Mahmoud, A. E. D., Fawzy, M., Hosny, G., Obaid, A., Equilibrium, kinetic, and diffusion models of chromium(VI) removal using Phragmites australis and Ziziphus spina-christi biomass, Int. J. Environ. Sci. Technol. 18 (2021) 2125. doi: https://doi.org/10.1007/s13762-020-02968-7

3. Ballance, R., Bartram, J., eds., Water Quality Monitoring: A Practical Guide to the Design and Implementation of Freshwater Quality Studies and Monitoring Programmes, Spon Press, 1998.

doi: https://doi.org/10.4324/9780203476796

4. Zhang, M., Gao, B., Removal of arsenic, Methylene blue, and phosphate by biochar/AlOOH nanocomposite, Chem. Eng. J. 226 (2013) 286 doi: https://doi.org/10.1016/j.cej.2013.04.077

5. Badr, N. B. E., Al-Qahtani, K. M., Mahmoud, A. E. D., Factorial experimental design for optimizing selenium sorption on Cyperus laevigatus biomass and green-synthesized nano-silver, Alex. Eng. J. 59 (2020) 5219. doi: https://doi.org/10.1016/j.aej.2020.09.051

6. Arivoli, S., Venkatraman, B. R., Adsorption of copper ions by acid-activated low-cost carbon-kinetic, thermodynamic and equilibrium studies, Rasayan J. Chem. 1 (2008) 276.

7. Kamsonlian, S., Suresh, S., Majumder, C. B., Chand, S., Biosorption of $\mathrm{As}(\mathrm{III})$ from contaminated water onto lowcost palm bark biomass, Int. J. Curr. Eng. Technol. 2 (2012) 153.

8. Naik, O., Soparkar, P., Khan, A., Navale, S., Mapare, S., A Review on detection of arsenic in water, Asian J. Converg. Technol. 4 (2018) 1.

9. World Health Organization, ed., Guidelines for drinking-water quality, 4th ed, World Health Organization, Geneva, 2011.

10. Bissen, M., Frimmel, F. H., Arsenic - A review. Part I: Occurrence, toxicity, speciation, mobility, Acta Hydrochim. Hydrobiol. 31 (2003) 9. doi: https://doi.org/10.1002/aheh.200390025

11. Zhu, B., Fan, T., Zhang, D., Adsorption of copper ions from aqueous solution by citric acid modified soybean straw, J. Hazard. Mater. 153 (2008) 300. doi: https://doi.org/10.1016/j.jhazmat.2007.08.050

12. World Health Organization, Guidelines for drinking-water quality: First addendum to the third edition, volume 1: recommendations, Geneva: WHO, (2006).

13. El-Araby, H. A., Ibrahim, A. M. M. A., Mangood, A. H., Abdel-Rahman, A. A.-H., Sesame husk as adsorbent for copper(II) ions removal from aqueous solution, J. Geosci. Environ. Prot. 05 (2017) 109. doi: https://doi.org/10.4236/gep.2017.57011
14. Hemavathy, R. V., Kumar, P. S., Kanmani, K., Jahnavi, N., Adsorptive separation of $\mathrm{Cu}$ (II) ions from aqueous medium using thermally/chemically treated Cassia fistula based biochar, J. Clean. Prod. 249 (2020) 119390. doi: https://doi.org/10.1016/j.jclepro.2019.119390

15. Hegazi, H. A., Removal of heavy metals from wastewater using agricultural and industrial wastes as adsorbents, HBRC Journal 9 (2013) 276. doi: https://doi.org/10.1016/j.hbrcj.2013.08.004

16. Mahmoud, A. E. D, Fawzy, M., Radwan, A., Optimization of Cadmium $\left(\mathrm{Cd}^{2+}\right)$ removal from aqueous solutions by novel biosorbent, Int. J. Phytoremediation 18 (2016) 619. doi: https://doi.org/10.1080/15226514.2015.1086305

17. Sulaymon, A., Biosorption of heavy metals: A review, J. Chem. Sci. Tech. 3 (2014) 74.

18. Kour, J., Homagai, P. L., Cagnin, M., Masi, A., Pokhrel, M. $R$., Ghimire, K. N., Adsorption of $\mathrm{Cd}(\mathrm{II}), \mathrm{Cu}(\mathrm{II})$, and $\mathrm{Zn}(\mathrm{II})$ from aqueous solution onto nitrogen-functionalized Desmostachya bipinnata, J. Chem. 2013 (2013) 1. doi: https://doi.org/10.1155/2013/649142

19. Pehlivan, E., Altun, T., Parlayici, S., Modified barley straw as a potential biosorbent for removal of copper ions from aqueous solution, Food Chem. 135 (2012) 2229. doi: https://doi.org/10.1016/j.foodchem.2012.07.017

20. Ulfa, S. M., Chamidah, N., Kurniawan, A., Adsorption of $\mathrm{Cu}(\mathrm{II})$ in aqueous solution by modified sawdust cellulose, IOP Conf. Ser.: Earth Environ. Sci. 239 (2019) 012008 doi: https://doi.org/10.1088/1755-1315/239/1/012008

21. Irem, S., Islam, E., Khan, Q. M., Anwar ul Haq, M., Hashmat, A. J., Adsorption of arsenic from drinking water using natural orange waste: Kinetics and fluidized bed column studies, Water Sci. Technol.: Water Supply. 17 (2017) 2017009. doi: https://doi.org/10.2166/ws.2017.009

22. Shakoor, M. B., Niazi, N. K., Bibi, I., Shahid, M., Sharif, F., Bashir, S., Shaheen, S. M., Wang, H., Tsang, D. C. W., Ok, Y. S., Rinklebe, J., Arsenic removal by natural and chemically modified watermelon rind in aqueous solutions and groundwater, Sci. Total Environ. 645 (2018) 1444. doi: https://doi.org/10.1016/j.scitotenv.2018.07.218

23. Pholosi, A., Naidoo, E. B., Ofomaja, A. E., Enhanced arsenic (III) adsorption from aqueous solution by magnetic pine cone biomass, Mater. Chem. Phys. 222 (2019) 20. doi: https://doi.org/10.1016/j.matchemphys.2018.09.067

24. Oyedeji, O. A., Osinfade, G. B., Removal of copper (II), iron (III), and lead (II) ions from mono-component simulated waste effluent by adsorption on coconut husk, Afr. J. Environ. Sci. Technol. 4 (2010) 382. doi: https://doi.org/10.5897/AJEST09.224

25. Mohani, N., Ahmad, M., Jahan, N., Evaluation of phytoconstituents of three plants Acorus calamus linn. Artemisia absinthium Linn and Bergenia himalaica boriss by FTIR spectroscopic analysis, Pak. J. Pharm. Sci. 27 (2014) 2251.

26. Imam, H., Riaz, Z., Azhar, M., Sofi, G., Hussain, A., Sweet flag (Acorus calamus Linn.): An incredible medicinal herb, Int. J. Green Pharm. 7 (2013) 288. doi: https://doi.org/10.4103/0973-8258.122053

27. Mahmoud, A. E. D., Franke, M., Stelter, M., Braeutigam, P., Mechanochemical versus chemical routes for graphitic precursors and their performance in micropollutants removal in water, Powder Technol. 366 (2020) 629. doi: https://doi.org/10.1016/j.powtec.2020.02.073

28. Nethaji, S., Sivasamy, A., Mandal, A. B., Adsorption isotherms, kinetics and mechanism for the adsorption of cationic and anionic dyes onto carbonaceous particles prepared from Juglans regia shell biomass, Int. J. Environ. Sci. Technol. 10 (2013) 231. doi: https://doi.org/10.1007/s13762-012-0112-0 
29. Mahmoud, A. E. D., Graphene-based nanomaterials for the removal of organic pollutants: Insights into linear versus nonlinear mathematical models, J. Environ. Manag. 270 (2020) 110911.

doi: https://doi.org/10.1016/j.jenvman.2020.110911

30. Oke, I. A., Olarinoye, N. O., Adewusi, S. R. A., Adsorption kinetics for arsenic removal from aqueous solutions by the untreated powdered eggshell, Adsorption 14 (2008) 73. doi: https://doi.org/10.1007/s10450-007-9047-z

31. Prasad, K. S., Ramanathan, A. L., Paul, J., Subramanian, V., Prasad, R., Biosorption of arsenite $\left(\mathrm{As}^{3+}\right)$ and arsenate $\left(\mathrm{As}^{5+}\right.$ ) from aqueous solution by Arthrobacter sp. biomass, Environ Technol. 34 (2013) 2701. doi: https://doi.org/10.1080/09593330.2013.786137

32. Adeogun, A. I., Idowu, M. A., Akiode, K. O., Ahmed, S. A. Bioremediation of $\mathrm{Cu}$ (II) contaminated water by Saccharum officinarum: Effect of oxalic acid modification on equilibrium, kinetic and thermodynamic parameters, Bioresour. Bioprocess. 3 (2016) 1. doi: https://doi.org/10.1186/s40643-016-0085-9

33. Saxena, M., Saxena, J., Evalution of phytoconstituents of Acorus calamus by FTIR and UV-vis spectroscopic analysis, IJBPR. 3 (2012) 498.

34. Ajaelu, C. J., Dawodu, M. O., Faboro, E. O., Ayanda, O. S., Copper biosorption by untreated and citric acid modified Senna alata leaf biomass in a batch system: Kinetics, equilibrium, absorption, surface area, thermodynamics, Isotherm, Phys. Chem. 7 (2017) 31.

doi: https://doi.org/10.5923/j.pc.20170702.02
35. Gong, R., Jin, Y., Chen, F., Chen, J., Liu, Z., Enhanced malachite green removal from aqueous solution by citric acid modified rice straw, J. Hazard Mater. 137 (2006) 865 doi: https://doi.org/10.1016/j.jhazmat.2006.03.010

36. Shrestha, B., Kour, J., Ghimire, K. N., Adsorptive removal of heavy metals from aqueous solution with environmental friendly material - exhausted tea leaves, Adv. Chem. Engineer. Sci. 06 (2016) 525. doi: https://doi.org/10.4236/aces.2016.64046

37. Biswas, B. K., Inoue, J., Inoue, K., Ghimire, K. N., Harada, H., Ohto, K., Kawakita, H., Adsorptive removal of As(V) and $\mathrm{As}(\mathrm{III})$ from water by a $\mathrm{Zr}$ (IV)-loaded orange waste gel, J. Hazard Mater. 154 (2008) 1066. doi: https://doi.org/10.1016/j.jhazmat.2007.11.030

38. Niazi, N. K., Bibi, I., Shahid, M., Ok, Y. S., Shaheen, S. M., Rinklebe, J., Wang, H., Murtaza, B., Islam, E., Nawaz, M. F., Lüttge, A., Arsenic removal by Japanese oak wood biochar in aqueous solutions and well water: Investigating arsenic fate using integrated spectroscopic and microscopic techniques, Sci. Total Environ. 621 (2018) 1642 doi: https://doi.org/10.1016/j.scitotenv.2017.10.063

39. Ansari, A., Daigavane, P. B., Analysis and modelling of slope failures in municipal solid waste dumps and landfills: A review, Nat. Environ. Pollut. Technol. 20 (2021) 825. doi: https://doi.org/10.46488/NEPT.2021.v20i02.045

40. Paudel, D. R., Poudel, B. R., Removal of arsenic from the aqueous solution by using the Fe(III)-loaded bioadsorbent, J. Nepal Chem. Soc. 32 (2013) 4. 